\title{
Spatial Analysis of Pre-Hospital Emergency Bases in Disasters in Tehran Province, Iran
}

\section{Zahra Mollamohammad Alian Mehrizi ${ }^{1} \oplus$, Seyed Ahmad Mirshojaee ${ }^{2}$}

\author{
Date of submission: 24 Jan. 2021 Date of acceptance: 3 Feb. 2021
}

Abstract

\section{Original Article}

INTRODUCTION: Tehran is always exposed to various dangers due to its high population density. A geographic information system (GIS) can be very useful for reducing the financial and human burden caused by accidents, disasters, and diseases.

METHODS: This field study was performed using a practical and descriptive research method. The pre-hospital emergency bases in the east of Tehran province and all the emergency bases covered by Shahid Beheshti University of Medical Sciences in disasters were evaluated as a case study. The population of these cities amounted to $1,149,485$ people and included cities in the east of Tehran province, Iran, including Damavand, Firoozkooh, Pakdasht, Pishva, Qarchak, and Varamin.

FINDINGS: Rational maps were created and analyzed in the areas where emergency bases were located using ArcGIS software, as well as analysis of regions, distances, point density, and a combination of these factors. Regarding the standards and indicators, it was determined that the Disaster and Emergency Medical Management Center needs to have13o emergency medical technicians, 23 ambulances, and one ambulance bus to equip the exiting emergency bases according to the standard pre-hospital regulations. Other requirements in this regard include the replacement of worn-out ambulances with new ones, construction of two emergency bases in Qarchak, Tehran, Iran, and three emergency bases in Pakdasht, Tehran, Iran, as well as the transfer of bases in the proximity of faults and flood-prone areas to safe places.

CONCLUSION: Based on the obtained results, a comprehensive pre-hospital database was designed for the use of managers and officials in the occurrence of accidents, which might be used as a pilot work that can be expanded to other areas of Tehran, Iran, and other provinces in managing disasters and accidents.

Keywords: Geographic Information System; Management of Accident; Pre-hospital Emergency; Spatial Analysis

How to cite this article: Mollamohammad Alian Mehrizi Z, Mirshojaee SA. Spatial Analysis of PreHospital Emergency Bases in Disasters in Tehran Province, Iran. Sci J Rescue Relief 2021; 13(1): 61-76.

\section{Introduction}

ost of the deaths and disabilities caused

$\mathrm{M}$ by accidents occur in the interval of the injured or sick person's transfer from the accident site to the hospital. In this regard, the preparedness of prehospital emergency bases, as the front line of the Ministry of Health, is very important before and during the crisis. While there is considerable evidence of patient care, there is ample evidence that shows patients get better results from the treatment team when they receive timely, prompt, and appropriate care in the pre-hospital phase (1).

The financial burden of disabilities and the mortality rate will be reduced through the proper management of pre-hospital emergency resources and facilities, proper access to all parts of the province, especially densely populated areas, provision of first aid, and timely rescue of patients and victims' lives. Although only three decades have passed since the official launch of the emergency medical system, ample evidence

1-Assistant Professor, Applied Science Higher Education Institute Red Crescent Society of the Islamic Republic of Iran, Tehran, Iran 2-Master of DMIS, Tehran, Iran

Correspondence to: Zahra Mollamohammad Alian Mehrizi, Email: zmehrizi@yahoo.com 
shows that this system has provided valuable services to the health system in this short period of time (2).

Regarding the data integration capabilities of the geographic information system (GIS) as well as the possibility of performing complex analyzes of spatial and non-spatial data, this system is considered the best decision-making tool in the management of the crisis. Moreover, GIS can be used to locate pre-hospital emergency bases before the crisis and identify high-risk areas in times of accidents.

Much scientific research has been conducted inside and outside the country to study the situation of emergency services and other relief organizations in the cities. Some examples of these researches have been considered in the present study.

Moghaddasi et al. (2014) conducted a comparative study on pre-hospital emergency information systems in the United States and the United Kingdom on the components of an information system including data, hardware and software, people, as well as the processing of data, reports, and information. The result was the design and creation of a national pre-hospital emergency information system and the provision of hardware and software systems and equipment for

the management of pre-hospital emergency information regarding the mobile nature of emergency services. The possibility of extensive electronic processing has been proposed in this emergency service in order to meet the need for information. Furthermore, there is the possibility of reporting and receiving the required information based on user's searches at local, provincial, and national levels (3).

Talebi and Faryabi (2014) investigated the role of information systems in road accident management in their study entitled "Application of GIS in road accident management". This article introduces a provincial experience in the application of GIS in the field of transportation information analysis, especially road accidents. In this project, an attempt has been made to produce a model that predicts the probability of accidents in the West Azerbaijan roads through the design of software (GIS) and analyzing spatial and descriptive data of accidents using genetic methods. Moreover, this analysis was used to locate roadside emergency bases more easily and coordinate traffic police patrol plans (4).

In another study entitled "Site selection for post-earthquake relief centers using GIS and analytic hierarchy process (AHP)" Zebardast et al.

have proposed criteria for locating emergency bases according to environmental and physical capabilities after the examination of one area in Tehran, Iran, in terms of accident rate using GIS (5).

In a study conducted by Chen Albert et al. (2014), American Society of Civil Engineers, entitled "Ambulance service area considering the disturbance of disasters on transportation infrastructure" the impact of accidents was considered as a disruptive factor in the emergency medical service system. This study aimed to assess the area of emergency medical services after an accident and investigate the deviation of services before and after disruption in the emergency transport infrastructure (6).

A study conducted by Sari (2017), investigated the shortest response time for emergency vehicles, taking into account obstacles such as speed bumps, traffic lights, the condition of street parking, railways, and intersections that reduce the speed of emergency vehicles. These items were considered the coefficient of intervention time increase in this study and the results were compared with the shortest path and shortest-time path (7).

In another study, a powerful and emerging tool was optimized for solving random and dynamic problems encountered in operational research using dynamic approximate programming (ADP). Dependence on time-dependent information, such as the arrival time of the ambulance and its consequences, in the stage of modeling and optimization, leads to non-optimal decisions. Therefore, extensive parameters were used for the proposed algorithm in this study [8].

\section{Description of the studied area}

The studied area included the cities located at the east of Tehran province, Iran, including Varamin, Firoozkooh, Damavand, Pakdasht, Pishva, and Qarchak cities, which are under the supervision of Shahid Beheshti University of Medical Sciences in terms of pre-hospital emergency bases. The total, population of these six cities was estimated at $1,149,485$ people, who were distributed in 11 districts, 14 cities, 24 
villages, and 537 rural districts, according to the latest census. The length of the communication routes in these areas was estimated at $3,734 \mathrm{~km}$.

According to the information of the Statistics Unit of the Plan and Budget Organization of Iran (2017) (9), Varamin, Tehran, Iran, included two districts, two cities, and four villages, Firoozkooh Tehran, Iran, included two districts, two cities, and five villages, Damavand, Tehran, Iran, included two districts, five cities, and five villages, Pakdasht, Tehran, Iran, included two districts, three cities, and six villages, Pishva, Tehran, Iran, included two districts, one city, and two villages, and Qarchak, Tehran, Iran, included one district, one city, and two rural areas, at the time of conducting the general population and housing census in 2016.

\section{Methods}

This applied, descriptive-evaluative study was conducted based on library and field research method. Sampling was not performed in the present study and its statistical population included emergency bases in Tehran province. However, only pre-hospital bases in the areas covered by the Medical Emergency and Accident Management Center of Shahid Beheshti University of Medical Sciences were examined due to time constraints. The required information was obtained from relevant sources, such as the Iran National Cartographic Center, Statistical Centre of Iran, and the raw and basic information was gathered from the areas covered by the Medical Emergency and Accident Management Center of Shahid Beheshti University of Medical Sciences as well as oral interviews with respective experts.

The covered areas were the eastern cities of Tehran province, Iran, including Damavand, Varamin, Pakdasht, Qarchak, Pishva, and Firoozkooh. Such information as emergency bases, number of personnel, number of vehicles, latitude, and longitude of emergency bases, population, and geodatabase information were prepared separately for each city. After that, the GPS receiving points of the pre-hospital emergency bases, presented in minutes and seconds, were converted to understandable coordinates in the UTM coordinate system (as WGS_1984_UTM_Zone_39) and the points were correctly located on the map of each city.
Subsequently, a unit map was compiled for all six cities and was properly georeferenced.

In the following analysis, the urban and road bases have been distributed as a single map in each criterion, considering the location of faults, watercourses, earthquakes, and other hazards.

\section{Communication routes in the east of Tehran province}

The total length of communication routes in the east of Tehran province is specified in Table 1 and Map 1.

\section{Map data analysis in ArcGIS software}

Location of emergency bases in the studied areas

Map 2 presents seven information layers that show the location of pre-hospital emergency bases using ArcGIS software. Each color on the map indicates the emergency bases of a city.

The health of the manpower and facilities and equipment of an emergency base are prerequisites of proper and timely service in an accident and crisis by the relief forces. In case any of the mentioned sources have problems, the relief process will be disrupted. The following maps present the distance of pre-hospital emergency bases from potential hazards, floods, earthquakes, and access and communication routes.

\section{Distance from seismic points}

In Map 3, the distance from seismic points is prioritized from the highest risk (score 1) to the lowest risk (score 6) using ArcGIS software, twolayer integration, and analysis. The closest and the farthest places to risk get the lowest and highest scores, respectively. Moreover, the most dangerous and the least dangerous areas are marked in yellow and blue colors, respectively.

\section{Distance of emergency bases from flood points}

Map 4 presents the distance of pre-hospital emergency bases from flood-prone areas and is prepared by a combination of one vector and one raster layer and the distance analysis. The closer bases to the flood-prone areas get the lowest scores and the farther ones get the highest scores. In this map, the most and the least dangerous areas are marked in red and in dark blue, respectively. Moreover, Map 5 is the result of a combination of eight layers in ArcGIS software. Some bases are located in the path of flood-prone areas and should be moved to a safe place. 
Table 1. The length of communication routes in the studied area (extracted from the road layer by the author)

\begin{tabular}{|c|c|c|c|c|c|c|c|}
\hline Item & $\begin{array}{l}\text { Highway and } \\
\text { freeway }\end{array}$ & Asphalt road & Railway & $\begin{array}{l}\text { Dirt } \\
\text { road }\end{array}$ & Roadway & Trail & $\begin{array}{l}\text { Total } \\
\text { length }\end{array}$ \\
\hline $\begin{array}{l}\text { Length of } \\
\text { routs }\end{array}$ & $99 \mathrm{~km}$ & km 910 & $\mathrm{~km} 151$ & km 2067 & $\mathrm{~km} 340$ & $\mathrm{~km} 167$ & $\mathrm{~km} 3734$ \\
\hline
\end{tabular}

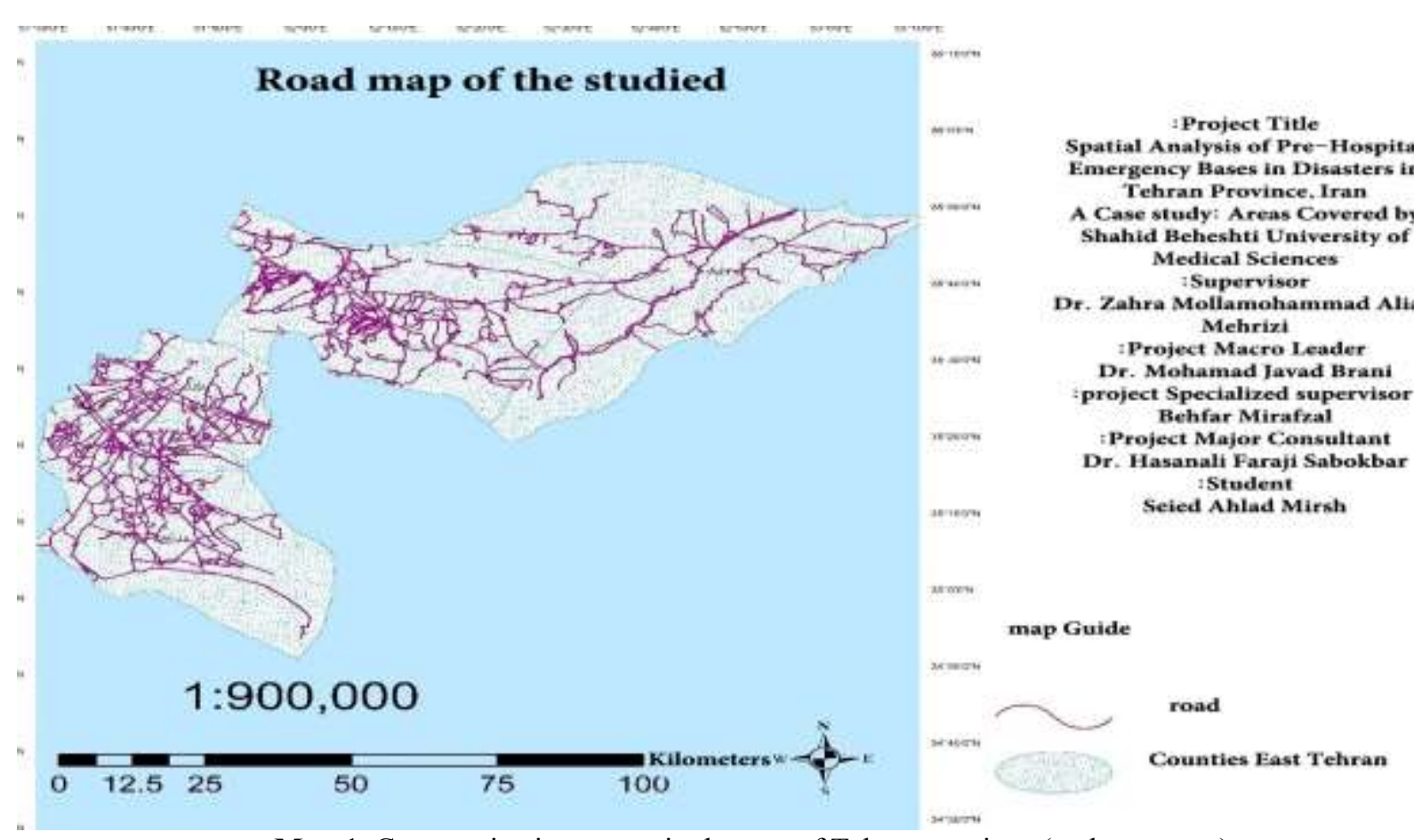

Map 1. Communication routes in the east of Tehran province (author source)
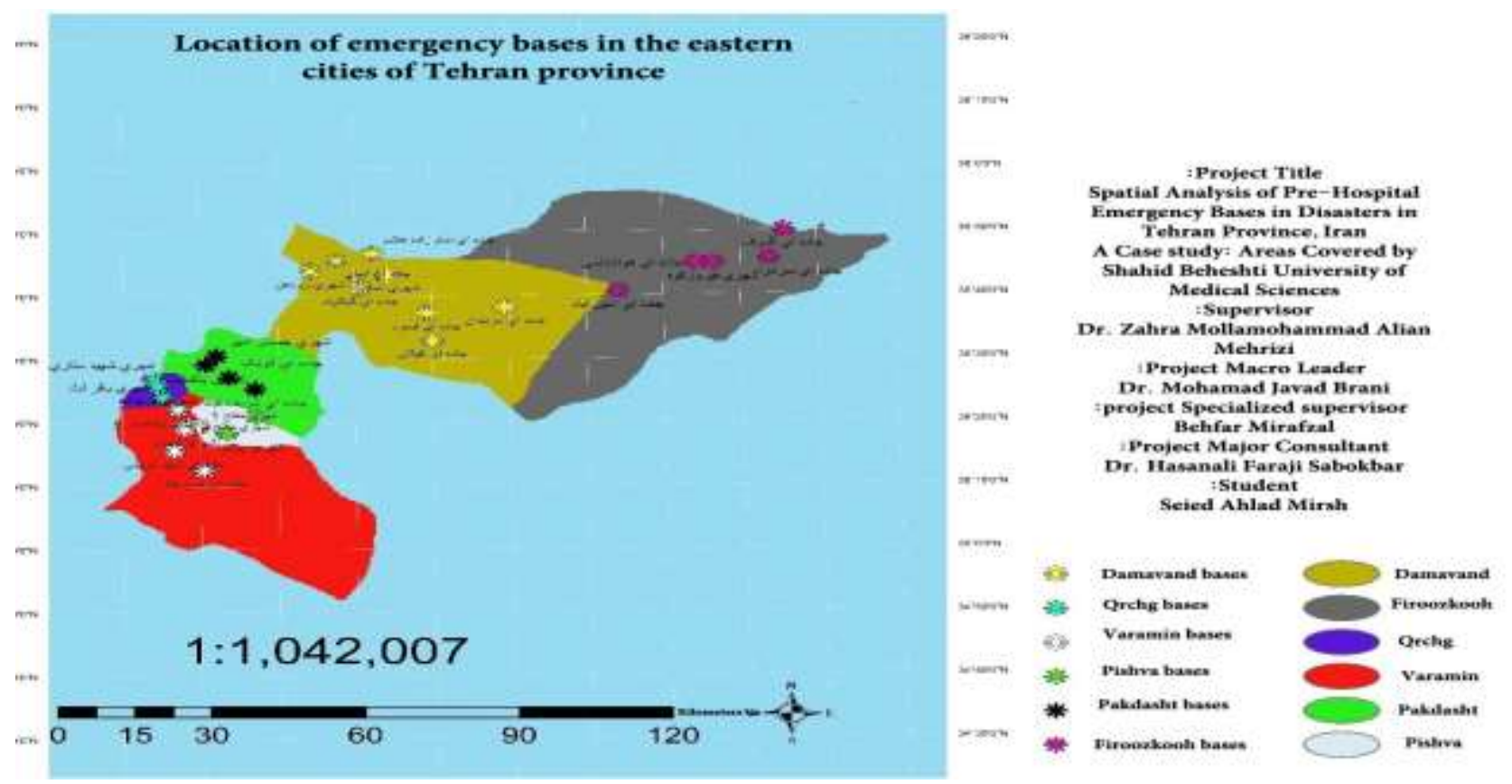

Map 2. Status of pre-hospital emergency bases (author source) 


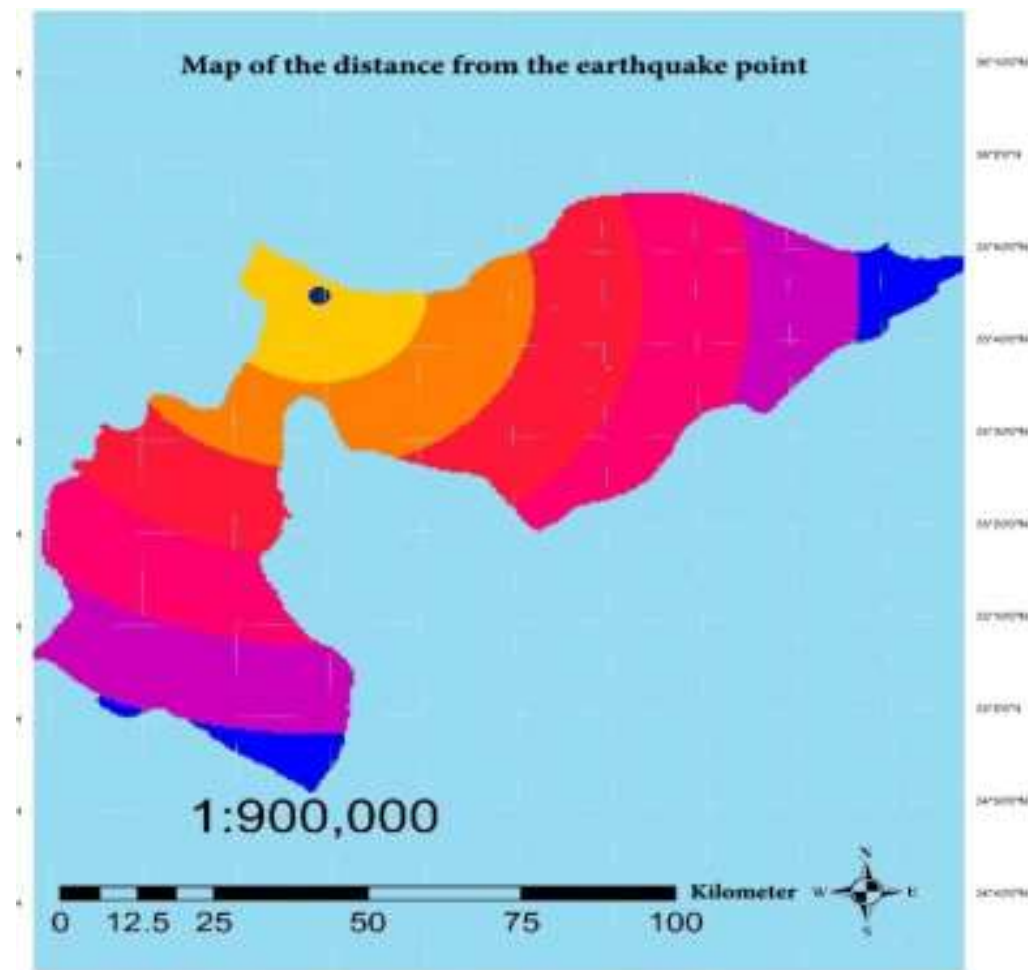

\author{
Project Tille \\ Spatial Analysis of Pre-Hespital \\ Emergency Bases in Disasters in \\ Tehran Province, Iran \\ A Case study: Areas Covered by \\ Shahid Beheshti University of Medical \\ Sciences \\ :Supervisor
Dr. Zahra Mollamohammad Alian \\ Mehrixi \\ Project Macro Leader \\ Dr. Mohamad Javad Brani \\ tproject Specialixed superviso \\ Behfar Mirafial \\ Project Major Consultant \\ Dr. Hasanali Faraji Sabekbar \\ :Student \\ Seied Ahlad Mirsh
}

- Earthequake points

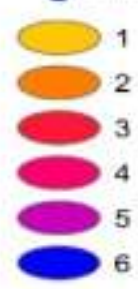

Map 3. Distance from earthquake points (author source)
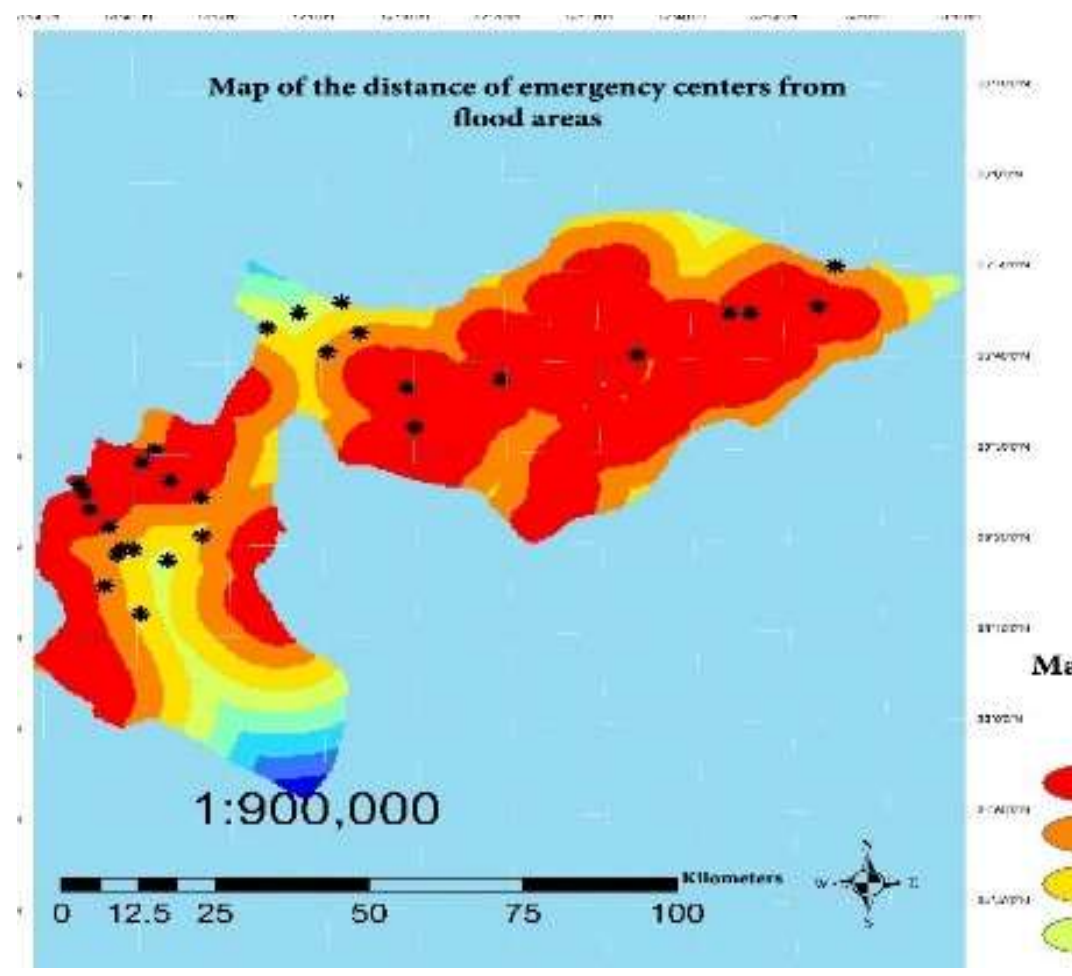

$$
\begin{aligned}
& \text { : Project Title } \\
& \text { Spatial Aralysis of Pre-Hospital } \\
& \text { Emergency Bases in Dixasters in Teluran } \\
& \text { Provinee, Iran } \\
& \text { A Cane study: A reses Covernd by Shahid } \\
& \text { Beheshti University of Medical Sciences } \\
& \text { :Supervisor } \\
& \text { ollamohammad Allan } \\
& \text { Mehrixi } \\
& \text { - Project Macro leader } \\
& \text { Dr. Muluamad Juvall Bruni } \\
& \text { project Specistized supervineor } \\
& \text { Behfar Mirafzal } \\
& \text { - Project Major Consultant } \\
& \text { Dr. Hasanali Farajt Sabolkbar } \\
& \text { : Student }
\end{aligned}
$$

Map 4. Distance from flood-prone areas and location of emergency bases (author source)

\section{Distance of emergency bases from the fault line}

Map 6 presents the distance of pre-hospital emergency bases from the fault line and is composed of eight layers graded from completely inappropriate to appropriate, respectively. The yellow and blue colors indicate completely 
inappropriate and appropriate places for constructing an emergency base, respectively. As is indicated in the map some bases are located near the fault line and should be moved from a high-risk location to a safe place.

\section{Map of distance from other hazards}

Map 7 presents distance from other hazards, such as snow, blizzard, and avalanche, and is composed of 2 layers. The most dangerous and the least dangerous areas for the construction of emergency bases are specified on the map in yellow and blue colors, respectively. Moreover, it is scored based on proximity to the danger areas. The closer and the farther areas to the danger zone get the lowest and the highest scores, respectively.

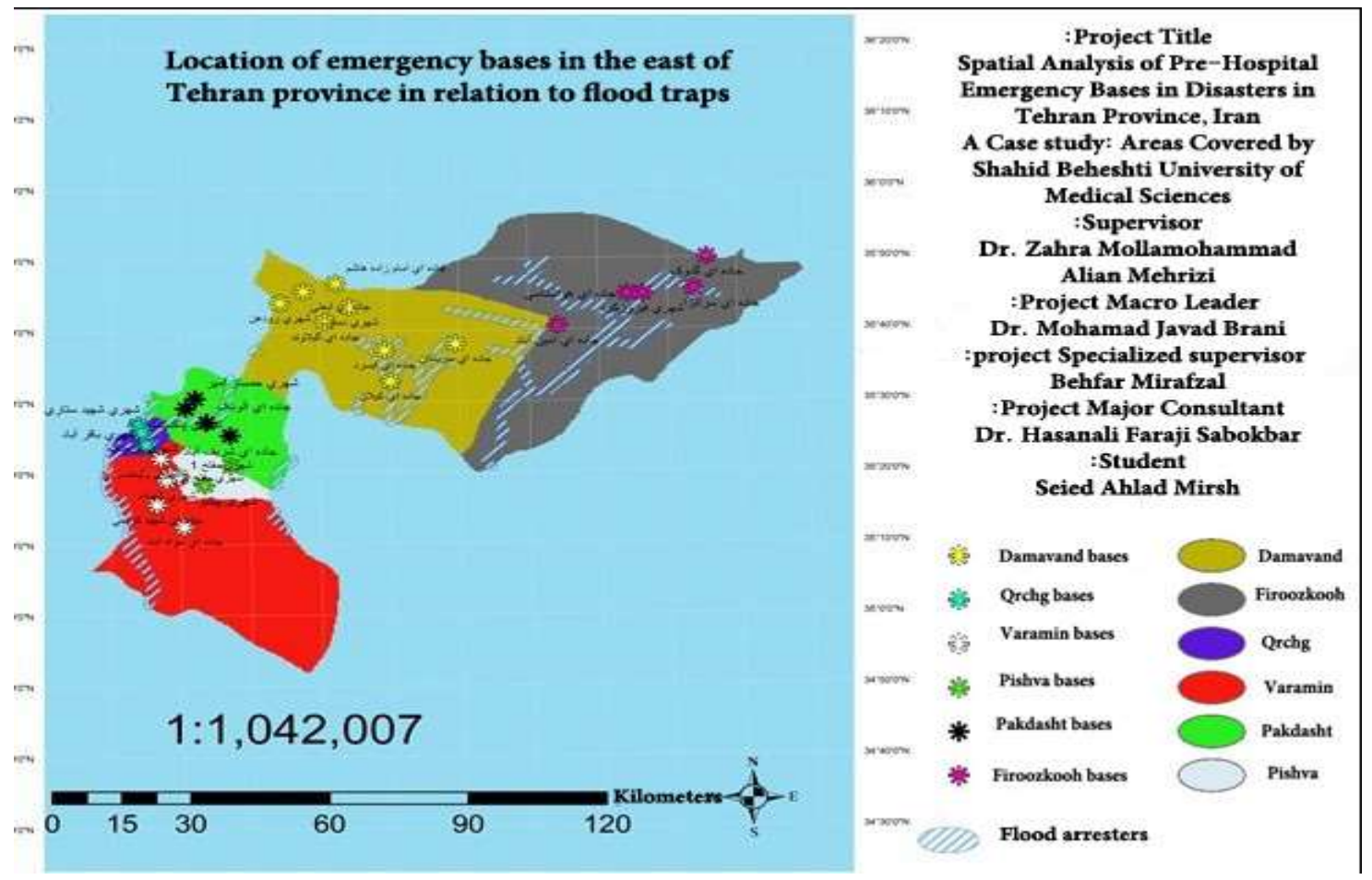

Map 5. Location of emergency centers in flood-prone areas (author source)
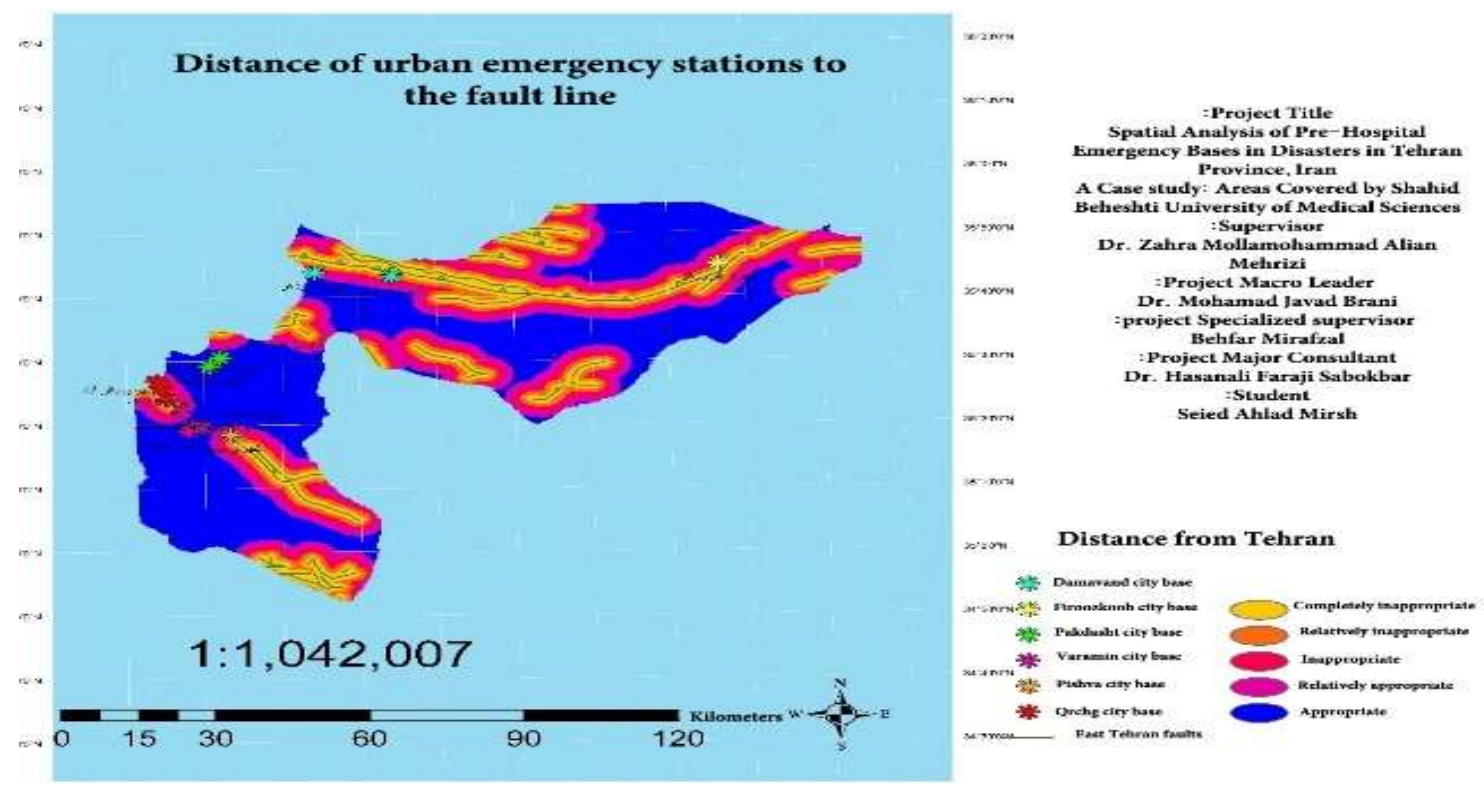

Map 6. Distance of emergency areas from the fault line (author source) 


\section{Risk rating map in areas}

Map 8 is the hazard map of the east of Tehran province, which is graded from safe to very highrisk areas. The safe areas are a good place for the construction of emergency bases.

\section{Distance of urban emergency bases from urban areas}

Map 9 presents the location of emergency bases by the city from a road at a distance from the urban areas of each city and is a combination of seven vectors and one raster layer using distance analysis. The proximity of bases to urban centers is regarded as appropriate and distance from urban centers is completely inappropriate, which are specified by yellow and blue colors on the map, respectively.

\section{Distance of road emergency bases from rural areas}

Map 10 presents the location of road emergency bases relative to the distance from rural areas. In this map, seven layers of information are combined and superimposed, with priority given to proximity to village bases. The closest bases (perfectly appropriate) and the farthest location to the village centers (completely inappropriate) get the highest and the lowest scores and are specified by green and red colors, respectively. The position of the bases can be evaluated regarding the deficits of these areas. In addition, Qarchak, Tehran, Iran, does not have a road emergency base and among the studied cities, Damavand, Tehran, Iran, possesses the most road bases with six emergency bases.
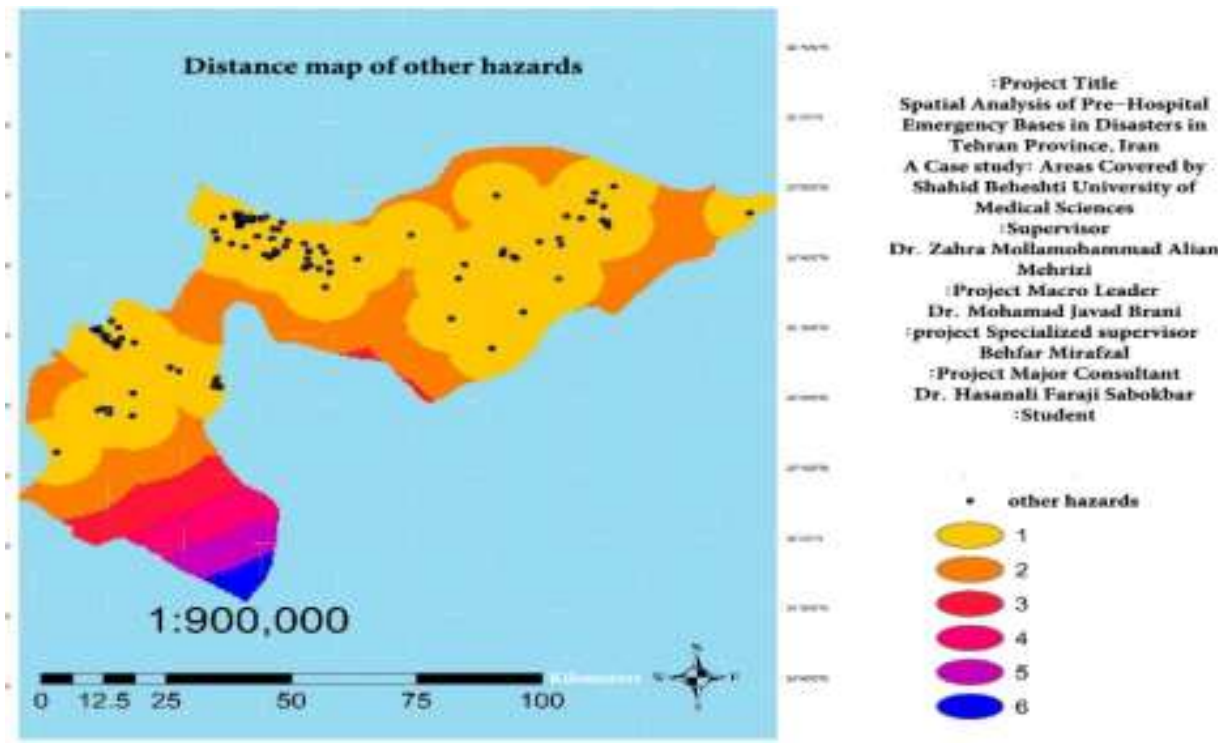

Map 7. Distance from other hazards (author source)
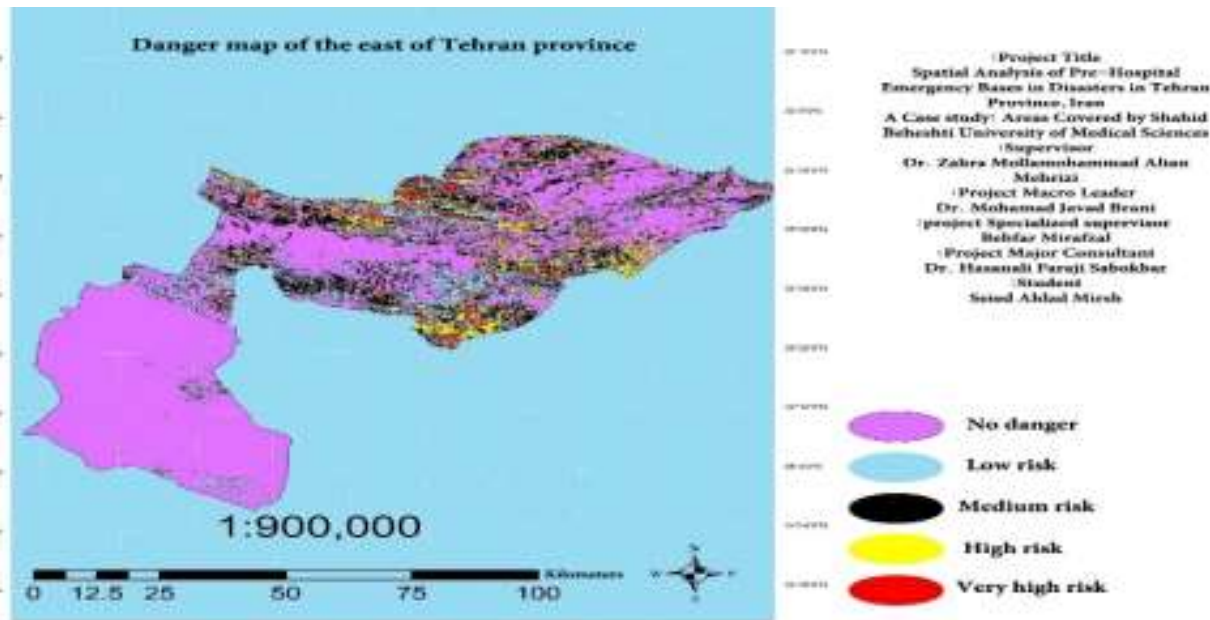

Map 8. Vulnerability of the eastern regions of Tehran province (author source) 


\section{Location of urban areas regarding the distance from faults:}

Map 11 presents the location of urban areas regarding the distance from faults and is a combination of three vector layers. The places are graded in terms of proximity (completely inappropriate) and distance (appropriate) from the fault line and are specified in red and green colors, respectively. Emergency bases can be set up in relatively appropriate to appropriate locations.

\section{Location of rural areas regarding the distance from faults}

Map12 is a combining three vector layers and presents the location of rural areas regarding the distance from faults. It is graded based on proximity to (completely inappropriate) and distance from the (appropriate) fault line. The appropriate and inappropriate location is shown in green and red, respectively.

\section{Position of urban emergency bases regarding urban population density:}

Map 13 presents the position of urban emergency bases regarding urban population density. The proximity of the emergency bases to densely populated areas accelerates the arrival of emergency base personnel in the accidents and disaster areas. This map is a combination of six vector layers and one raster layer. The distance and proximity to the densely populated areas receive the lowest and highest scores, respectively.
Furthermore, the black and red colors are indicative of low and high-density areas, respectively.

\section{Location of road emergency bases regarding the rural density:}

Map 14 presents the location of road emergency bases regarding the rural population density. The proximity of the emergency bases to densely populated centers accelerates the presence of emergency base personnel in the accidents and disaster areas. This map is a combination of five vectors and one raster layer in which the distance and proximity to the densest areas get the lowest and the highest scores, respectively. The black and red colors are indicative of the lowest and the highest density of rural areas, which is a good criterion for the construction of emergency bases regarding population density.

\section{Distance of road emergency bases from main roads}

Map 15 presents the distance from the main roads of the studied area. Due to the fact that all land, air and, rail access routes are disrupted during accidents and regarding the possibility of blocking the communication routes, the side roads are used as an alternative. The map is a combination of one vector and one raster layer and indicates the distances from and proximity to the main roads using distance analysis. Here, the proximity to and distance from the main road is indicated by yellow and blue colors that can be used as a guide for the construction of emergency bases.

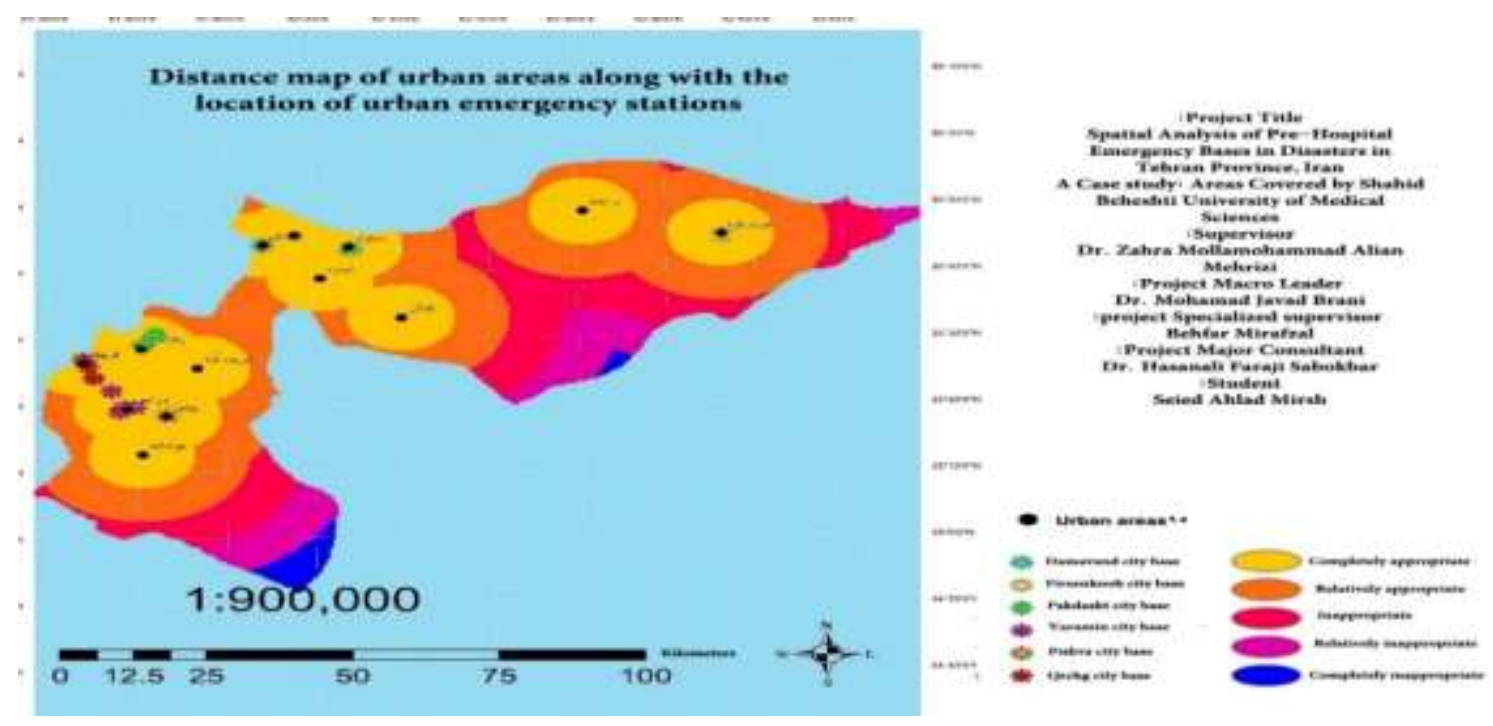

Map 9. Location of urban emergency bases regarding the distance from urban studied areas (author source) 

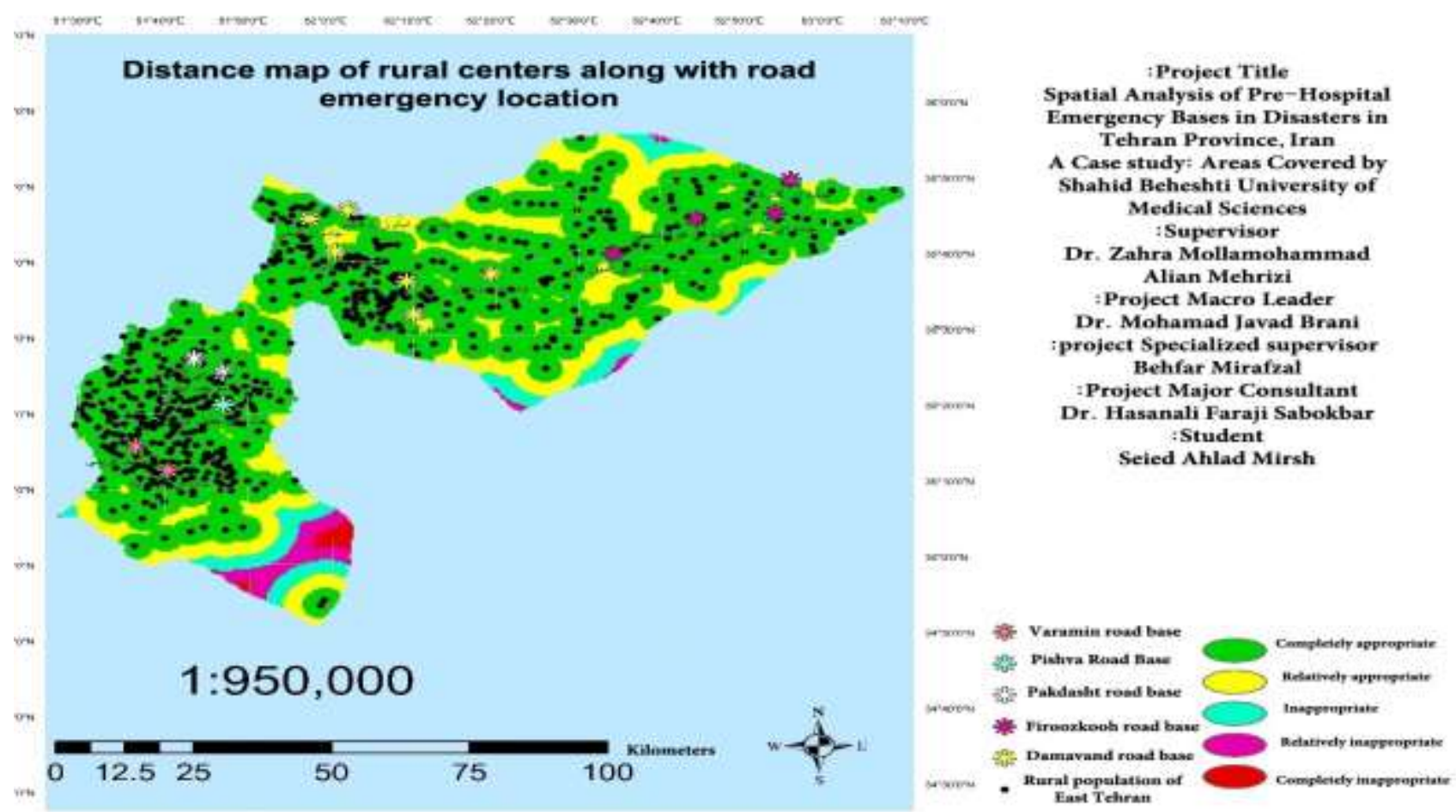

Map 10. Location of road emergency bases regarding the distance from rural areas (author source)
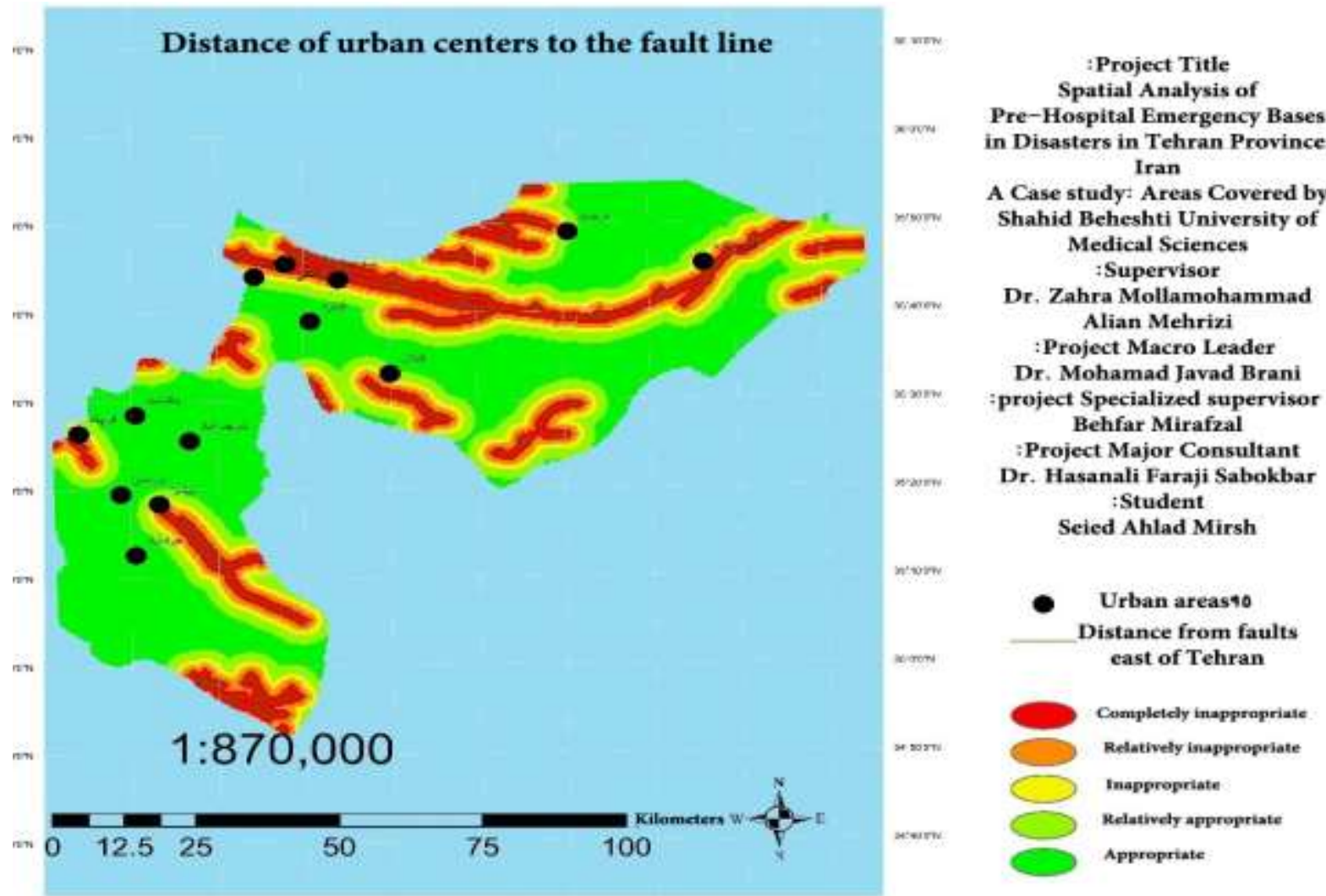

Map 11. Location of urban areas regarding the distance from faults (author source) 

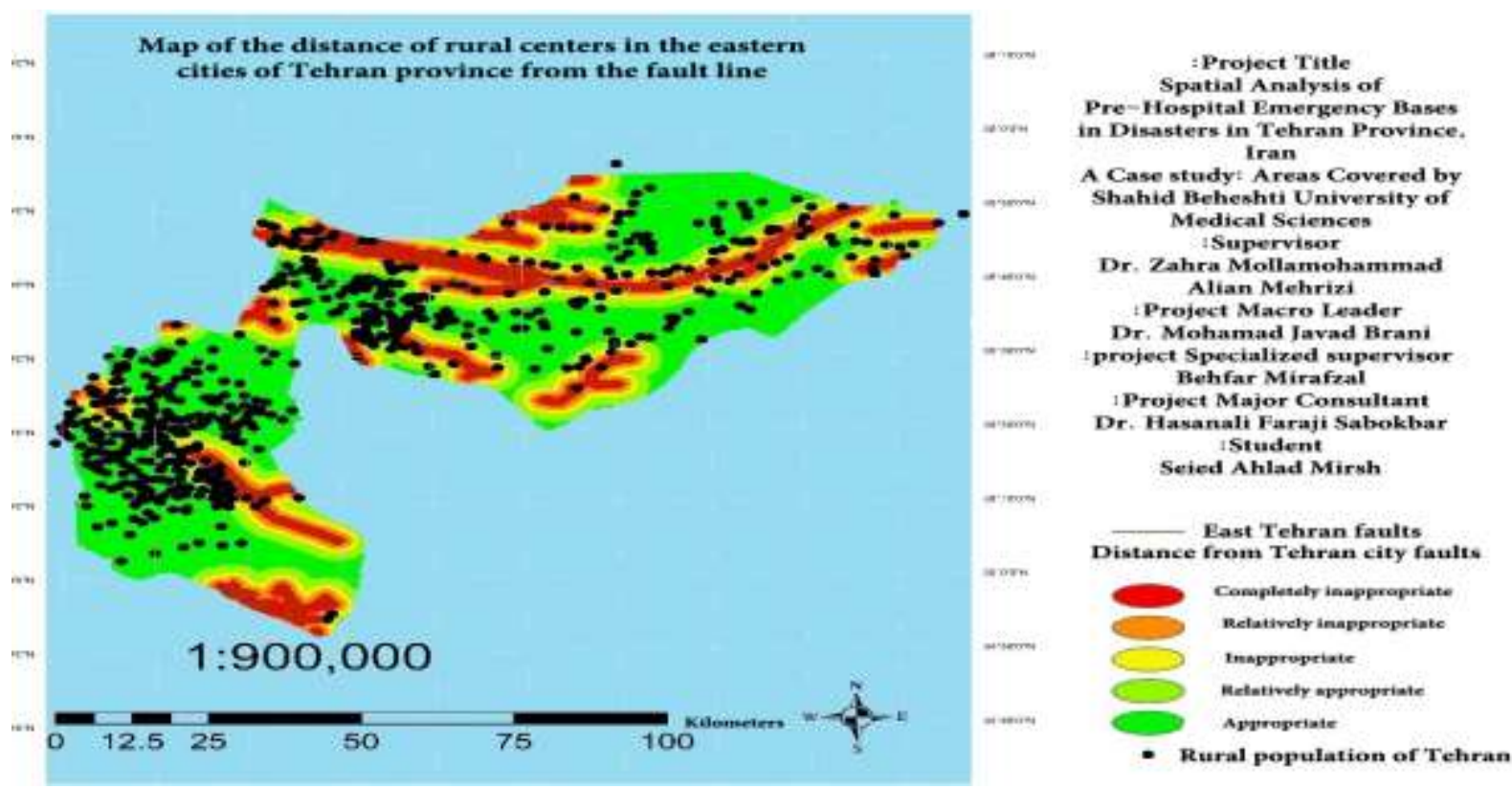

Map 12. The location of rural areas regarding the distance from the fault line (author source)
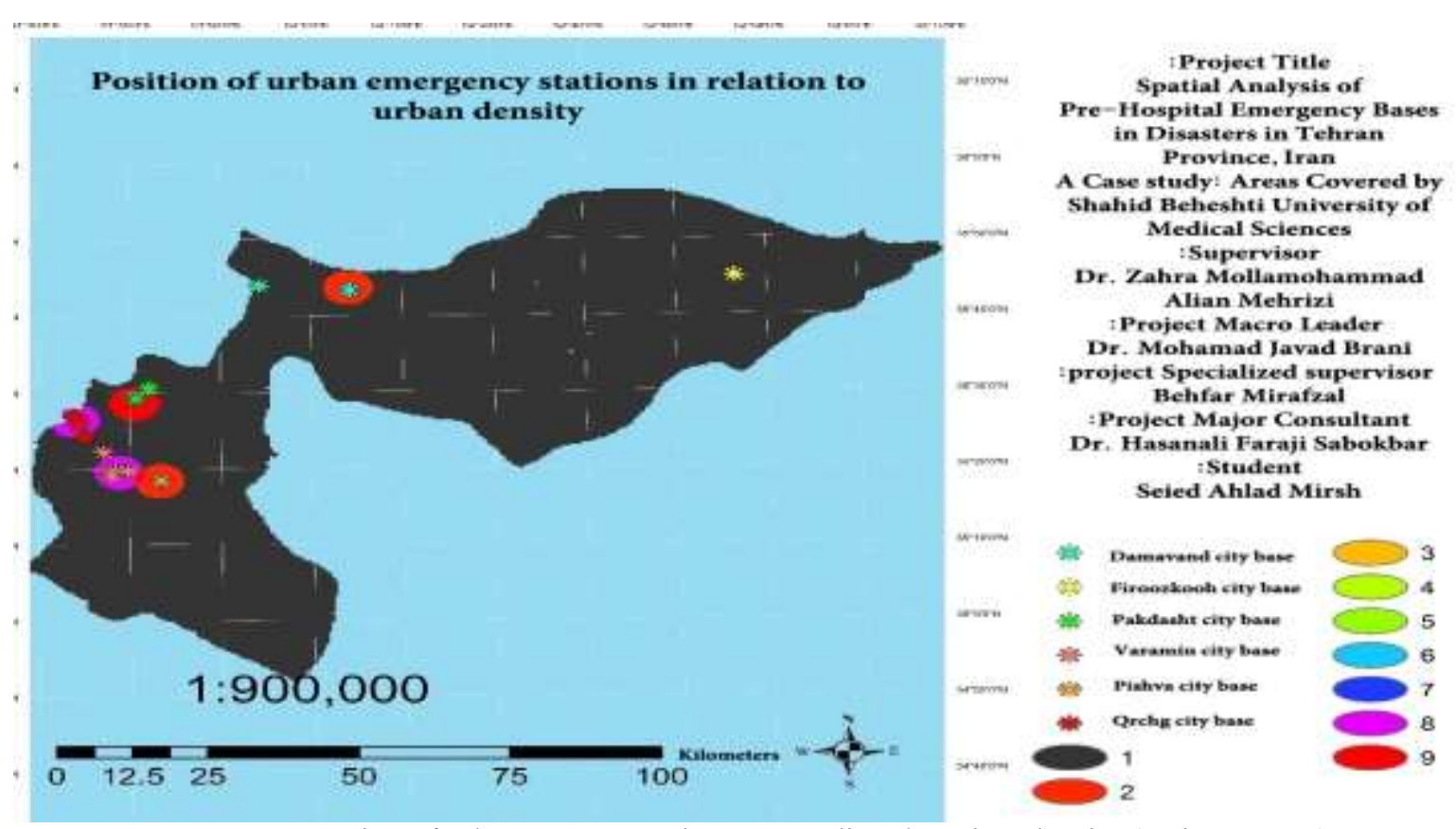

Map13. Location of urban emergency bases regarding the urban density (author source)

\section{Distance of road emergency bases from the railway}

Map 16 presents the distance of road emergency bases from the railway in the studied area. Considering the destruction probability of land roads as a result of accidents, it is possible to provide transportation services through other means of communication, such as railways. This map is a combination of one vector and one raster layer, and distances from and proximity to the railway have been determined using distance analysis. Moreover, the proximity to (the highest score) and distance from (the lowest score) the railway is shown in yellow and blue colors, respectively, which can be used as a guide for the construction of emergency bases. 

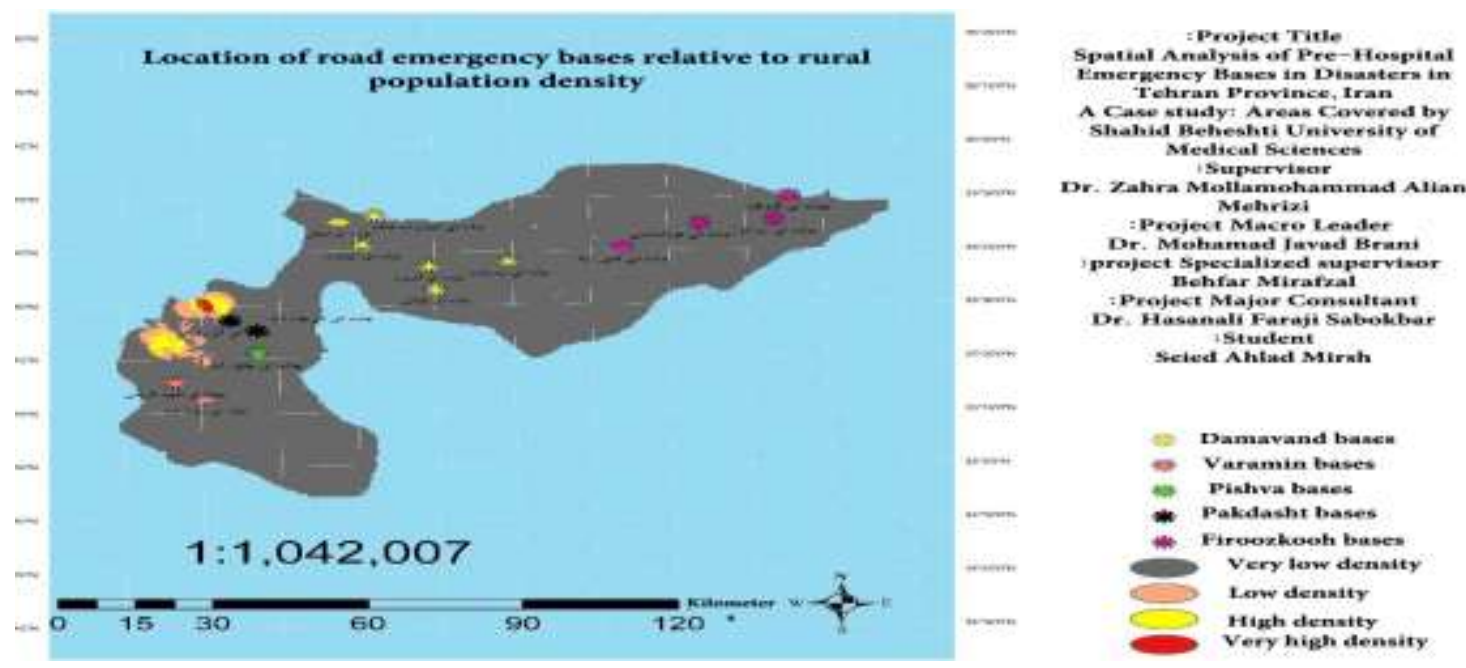

Map 14. Location of road emergency bases in relation to rural population density (author source)
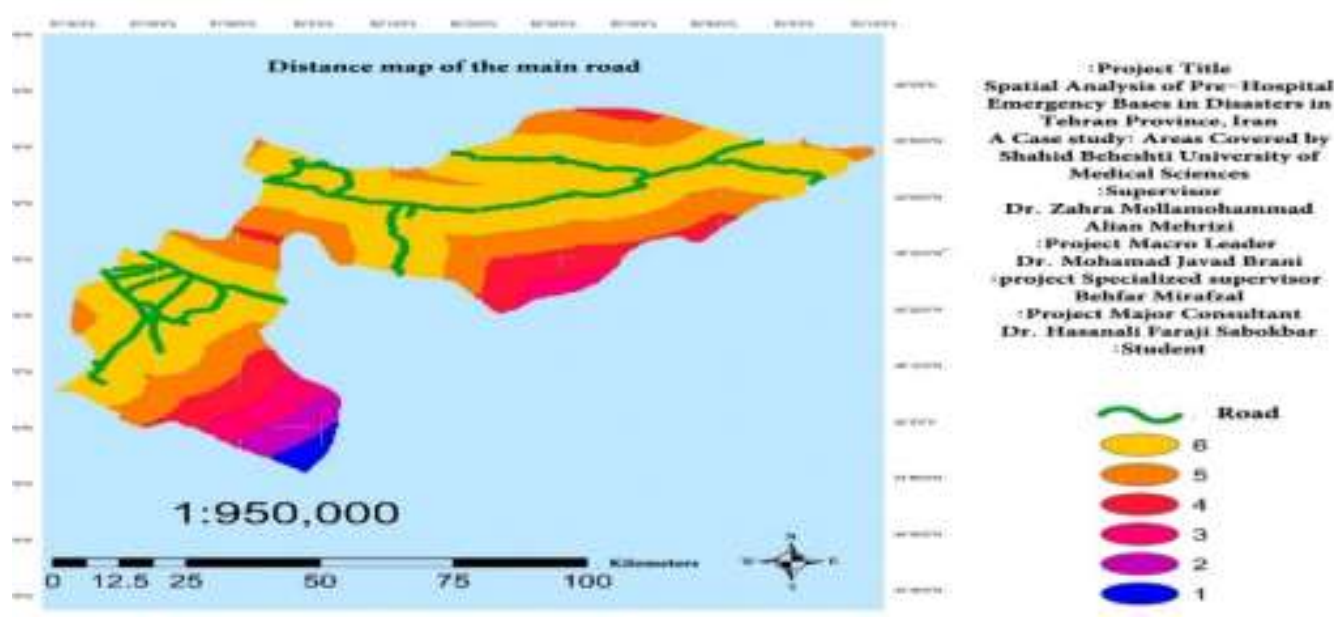

Map15. Distance of road emergency stations from main roads (author source)
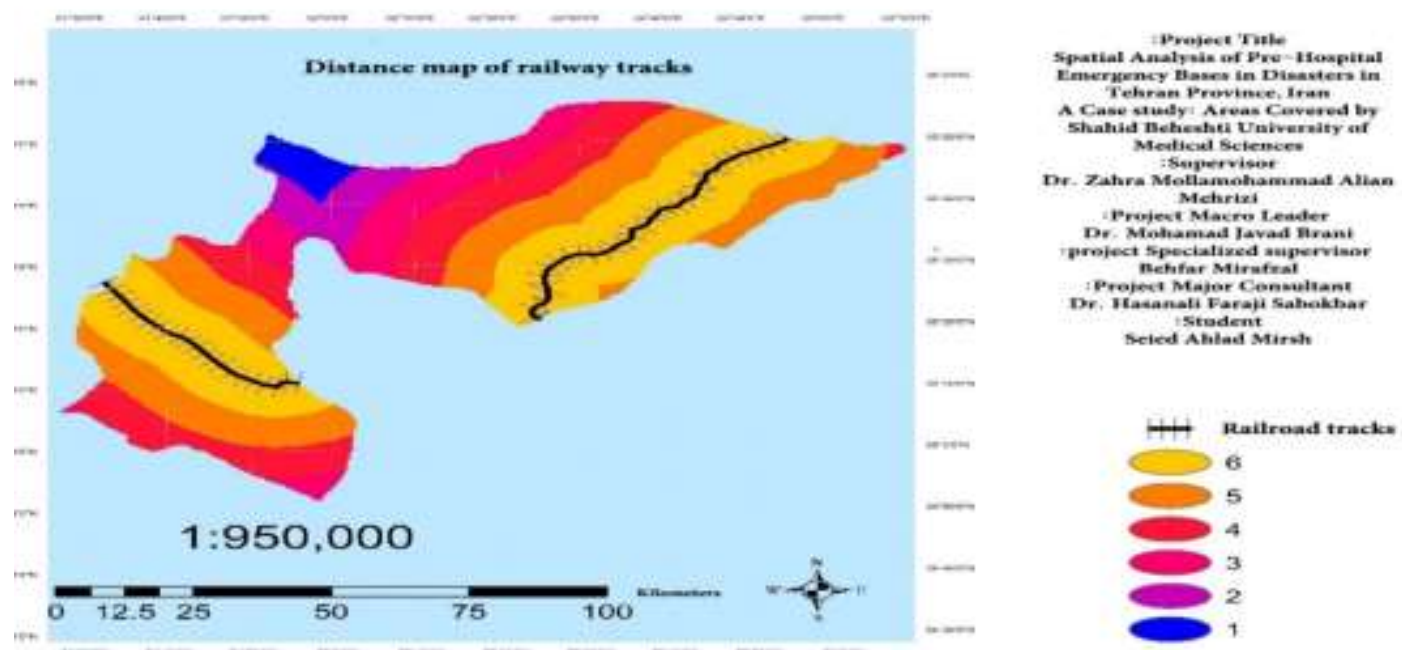

Map 16. Distance of road emergency bases from the railway (author source) 


\section{Discussion and Conclusion}

Today the need to reduce the effects of natural disasters in Tehran province through research and planning is felt more than ever. The reason for this is the geographical position of Tehran province, the importance of this city as the capital of the country, as well as its high population density. Therefore, major natural disasters and crises that can cause irreparable loss of life and property, such as floods and earthquakes threaten this city due to the existence of many faults. These natural disasters have happened in recent years and the probability of their recurrence is very high.

Iran Emergency Organization working under the Ministry of Health and Medical Education is one of the organizations responsible for transferring emergency support equipment from the accident scene to medical centers. Disaster and Emergency Medical Management Center of medical sciences university in each city is undertaking this mission in the areas covered by this center and provides emergency services to people through emergency bases.

The present study aimed to investigate the east of Tehran province in terms of spatial analysis of accidents in pre-hospital emergency bases (covered by Shahid Beheshti University of Medical Sciences) and three hypotheses are discussed in this regard:

Hypothesis 1: The status of resources and equipment of pre-hospital emergency bases in the areas covered by Shahid Beheshti University of Medical Sciences in Tehran is favorable considering the standard indices. However, regarding the information obtained from emergency bases and in comparison with indices and standards some shortcomings were observed in the pre-hospital centers under the study, which will be discussed in the following.

Regarding the respective standards and indicators, one ambulance bus should be allocated to every one million people to provide emergency medical services to patients in mass accidents and emergencies. Disaster and Emergency Medical Management Center of this university lack an ambulance bus (despite the population of $1,149,485$ people in this area) which should be provided by the Ministry of Health and Emergency.

Two ambulances have to serve in each urban emergency station in a 24-hour shift. Unfortunately, there is a deficit of 23 ambulances in the above urban areas that need to be compensated.

According to the last census in 1995, the rural population of the studied areas is 240,649 people. An agreement entitled the provision of emergency medical services to residents of rural, nomadic, and urban areas with a population of less than 50,000 people were reached between the deputy ministers of health and medical treatment and medical education on $07 / 07 / 2015$ with the letter number 308/8/10259. According to this agreement, the recipients of the emergency services include people in rural and nomadic areas, the residents of cities with a population of less than 50,000 people in the country. Moreover, villages with a population of less than 20,000 people, and cities with a population of between 20,000 to 50,000 people in the country are in priority of receiving the services. Currently, 15 road stations with one ambulance are available in non-urban areas that meet the standards.

According to the standards and indicators, six people must do shift work per each active ambulance. In other words, two people are needed for each ambulance in each 24-hour shift. Therefore, about 300 people are needed for these active emergency bases and ambulances. However, only 171 people are serving in these areas, and there is an obvious shortage of workforce.

The useful life of pre-hospital emergency ambulances is about 5 to 10 years. However, 40 ambulances out of a total of 61 ambulances in these areas have a lifetime of over 10 years and should be replaced with new ambulances.

Moreover, another important issue in this regard is the exact location of emergency bases regarding the possible dangers, including proximity to floodplains and faults. A solution needs to be found for these dangers to provide relief to the injured people and prevent damage to the emergency bases in times of crisis.

Regarding the above-mentioned issues, there are deficiencies in the resources and equipment of the areas covered by Shahid Beheshti University of Medical Sciences that need to be addressed in order to respond better and faster to the people of the region in the crises. This requires the great effort of the Ministry of Health and the country's emergency organization to resolve resource constraints before the occurrence of the crisis. 
Hypothesis 2: A comprehensive pre-hospital emergency information system is available for disaster management in the areas covered by Shahid Beheshti University of Medical Sciences in Tehran province, Iran.

Based on the field surveys and referrals to this center, there are no comprehensive information and map facilities available in the Medical Emergency and Accident Management Center of Shahid Beheshti University of Medical Sciences. To resolve this issue, an information bank has been created that provides resources and population census in one place for each city. The figure below presents an example of these databases that are connected to the map and geographical points and are geo-referenced.

Hypothesis 3: The current pre-hospital emergency bases are proportional to the population density of the respective areas in Tehran province.

The urban population of the studied area was estimated at 908,791 people according to the last census of 1995 and after reviewing the maps

and resources available in the pre-hospital emergency centers of the studied areas. Considering the standard, there must be one urban emergency base per 50,000 people. At present, there are 13 urban bases available in this region, while according to the standards, there must be 18 urban bases with two active ambulances. Therefore, there is a lack of about five urban bases in all cities specified in the following maps that will be resolved through the resources allocated by the Ministry of Health and the country's Emergency Organization.

\section{Distribution of pre-hospital emergency bases in Qarchak, Tehran, Iran}

The distribution of pre-hospital emergency bases in the studied areas shows that the population of Qarchak city amounts to 269,000 people $(231,075$ people in urban and 38,063 people in rural areas), according to the Statistical Center of Iran. The vastness of the area is $90 \mathrm{~km}^{2}$ in which three emergency bases exist. There is a need to build two more bases according to the standard and index of the regulation of comprehensive coverage of pre-hospital emergency medical services (Map $17)$.
Distribution of pre-hospital emergency bases in Damavand, Tehran, Iran

There are two urban and six road emergency bases in Damavand city with a population of about 125,000 people $(93,201$ urban and 32,279 rural people) in an area of $1905 \mathrm{~km}^{2}$. The distribution of emergency bases in this city is very desirable based on the standards (Map 18).

\section{Distribution of pre-hospital emergency bases in Pakdasht, Tehran, Iran}

There are two urban and two road emergency bases in Pakdasht, Tehran, Iran, which is the most populous city in the studied area, with a population of about 350,000 (276,282 are urban and 74,684 are rural) in an area of $675 \mathrm{~km}^{2}$. This condition is far below the standard in terms of the number of bases and will reach the desired level with the construction of three other bases (Map 19).

\section{Distribution of pre-hospital emergency bases in Firoozkooh, Tehran, Iran}

There are one urban and four road emergency bases in Firoozkooh, Tehran, Iran, with a population of about 34,000 people $(18,577$ people in urban and 14981 people in the rural area) in an area of about $2383 \mathrm{~km}^{2}$. The distribution ratio of these bases exceeds the density of population in this city (due to the large area and small population distribution of this city). Therefore, the number of bases in this area is higher than the standard (Map 20).

\section{Distribution of pre-hospital emergency bases in Pishva, Tehran, Iran}

There are one urban base and one road emergency base in Pishva, Tehran, Iran, with a population of about 86,000 people $(59,184$ people in the urban and 27,417 people in the rural area) in an area of $201 \mathrm{~km}^{2}$. The distribution of emergency bases is desirable based on the standard (Map 21).

\section{Distribution of pre-hospital emergency bases in Varamin, Tehran, Iran}

There are four urban and two road emergency bases in Varamin, Tehran, Iran, with a population of about 283,000 people $(230,472$ people in the urban and 53,270 people in the rural area) in an area of about $1541 \mathrm{~km}^{2}$. The distribution of 
emergency bases in this city is desirable according to related standards (Map 22).

National Cartographic Center has designed a comprehensive information pre-hospital center for the use of respective managers and officials at the occurrence of emergencies and disasters, which can be useful in the management of accidents as a pilot work that can be expanded to other areas of Tehran and other provinces. This pre-hospital center has been designed using such information as the location of bases, number of human resources, number of ambulances by type of vehicle, number of permanent and temporary emergency bases by city and road. Moreover, the demographic, topography, geology maps of the National Cartographic Center of Iran from the covered areas were integrated with the data taken from the emergency center using ArcGIS software. Various analyses were performed on output data obtained from the target areas and evaluated based on indicators and standards in terms of specific strengths and weaknesses.

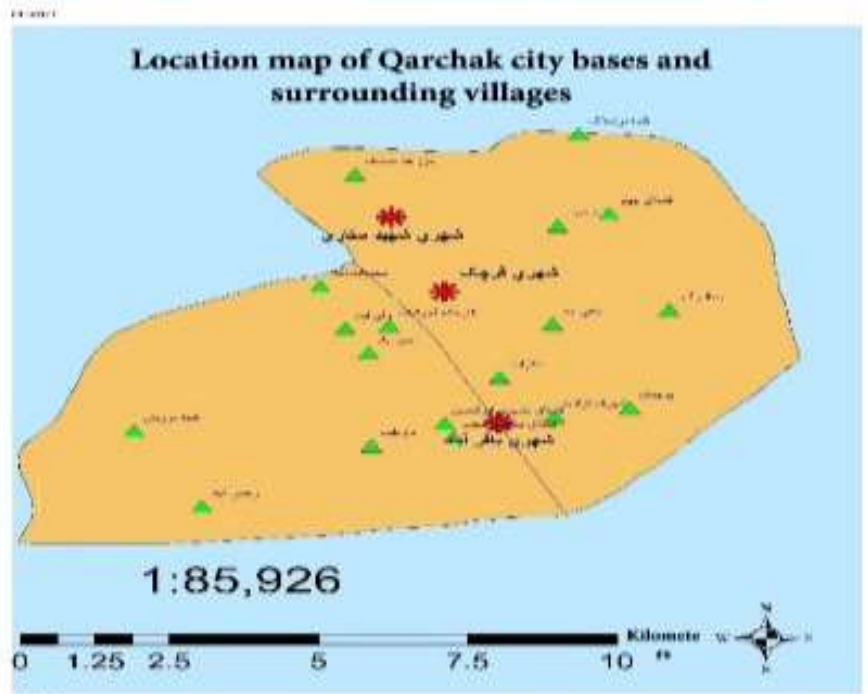

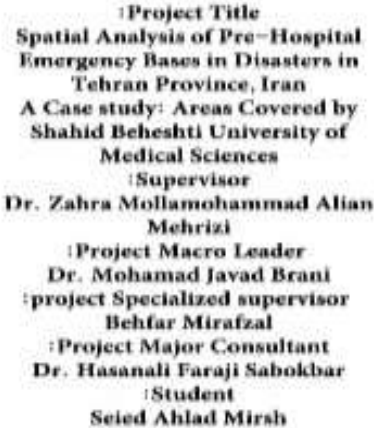

map Guide

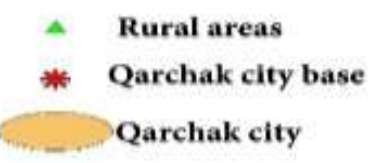

Map17. Location of Qarchak city bases \& surrounding villages (author source)
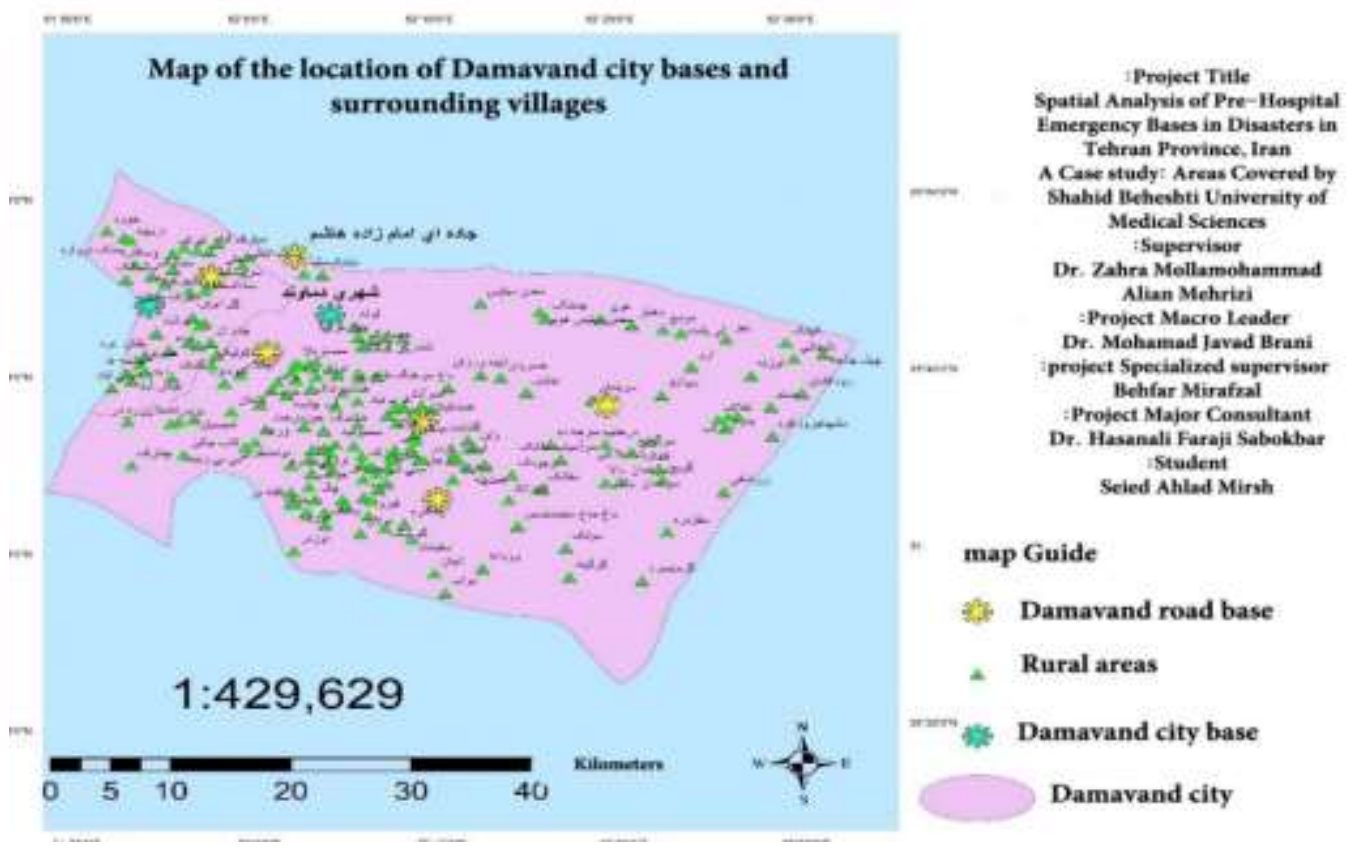

Map 18. Location of Damavand emergency bases (author source) 


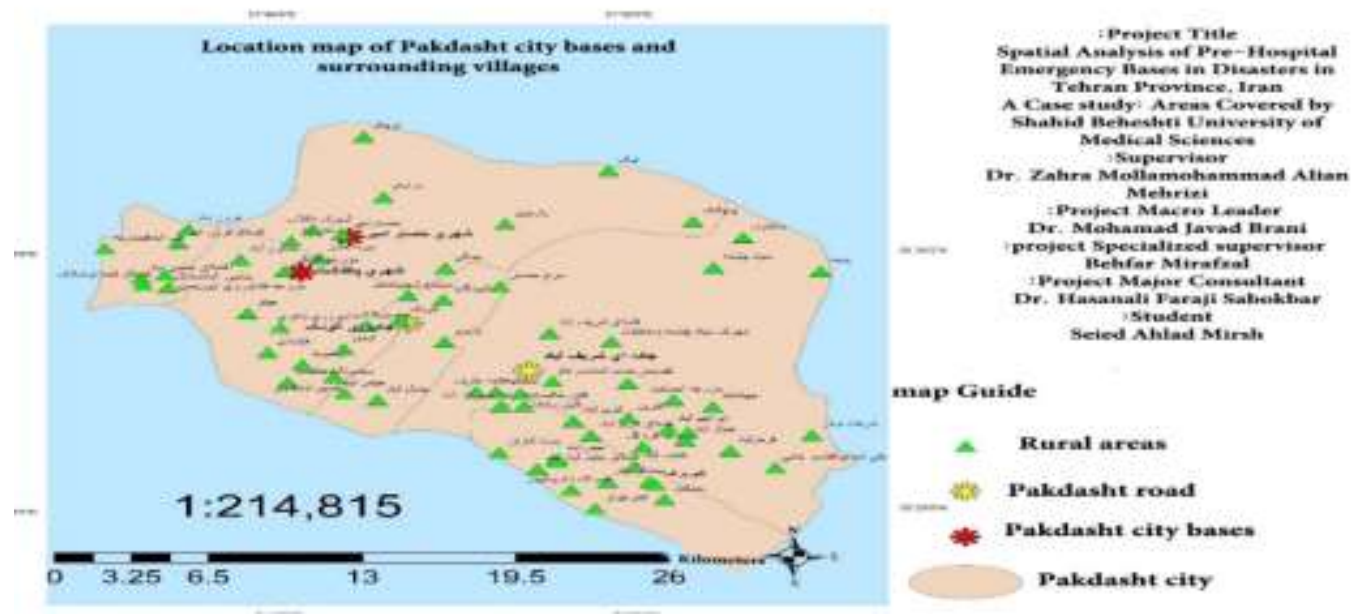

Map19. Location of Pakdasht emergency bases (author source)
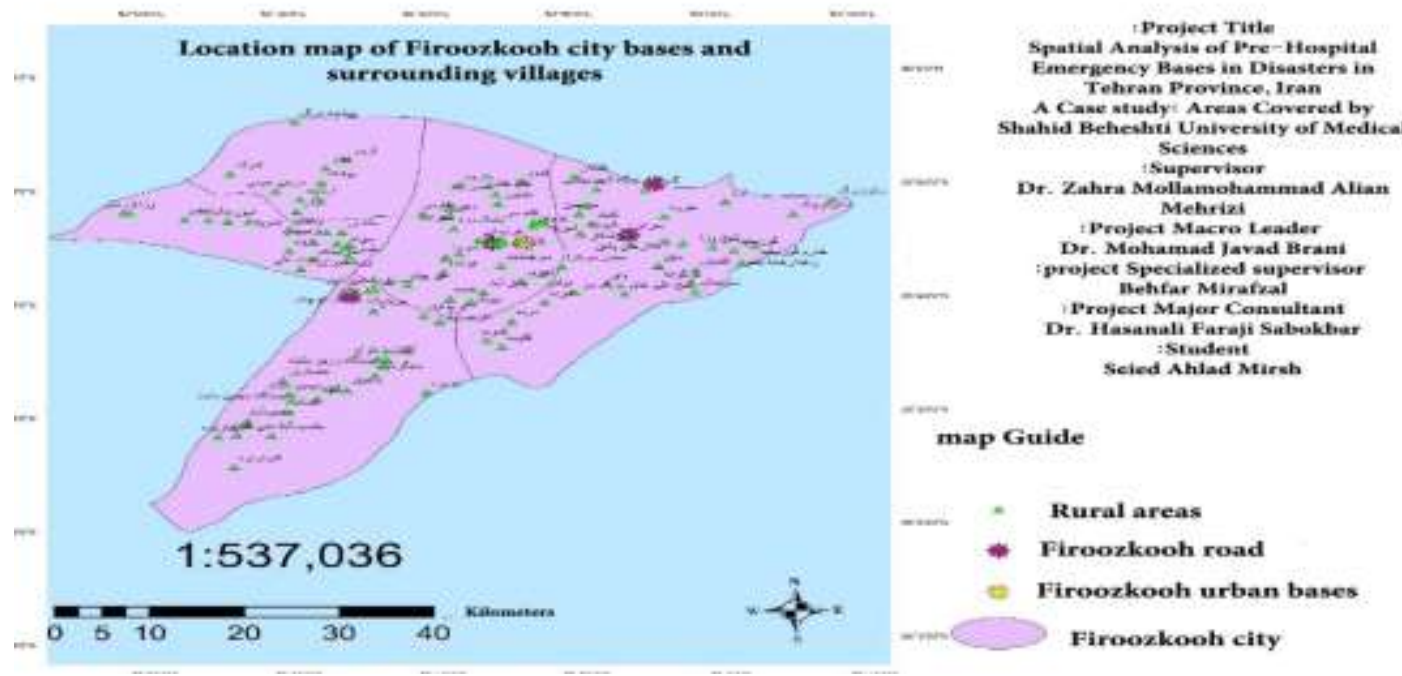

Map 20. Location of Firoozkooh Emergency bases (author source)
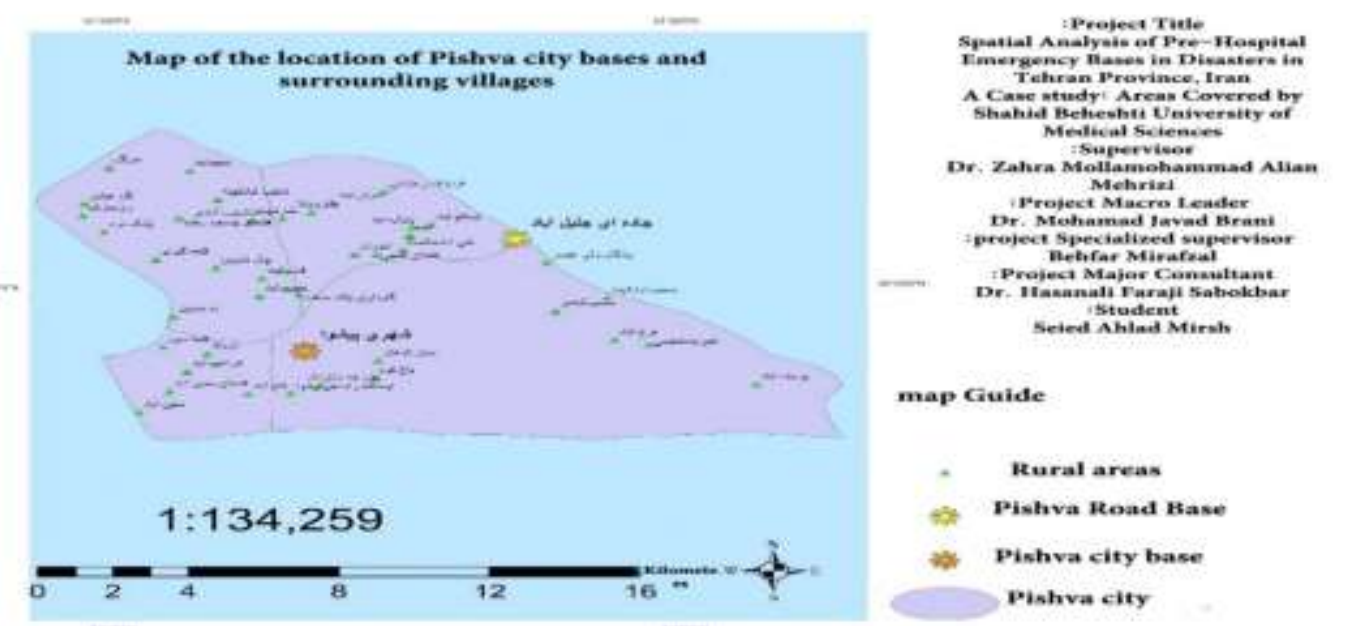

Map 21. Location of Pishva Emergency bases (author source) 


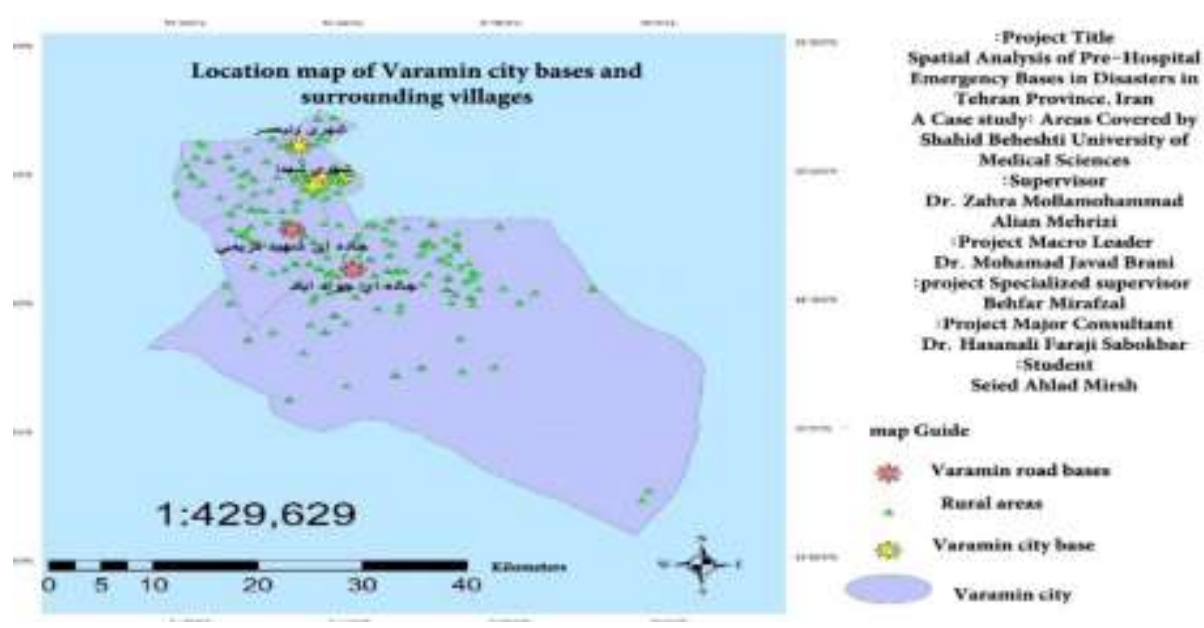

Map 22. Location of Varamin emergency bases (author source)

\section{Acknowledgments}

None

\section{Conflict of Interests}

Authors have no conflict of interests.

\section{References}

1. Karamizadeh Z, Zarifsanayei N, Faghihi AA, Mohammadi H, Habibi M. The study of effectiveness of blended learning approach for medical training courses. Iran Red Crescent Med J 2012; 14(1): 41.

2. Blackwell TH, Kaufman JS. Response time effectiveness: comparison of response time and survival in an urban emergency medical services system. Acad Emerg Med 2002; 9(4): 288-95.

3. Moghaddasi H, Rabiei R, Mastaneh Z, Movahedinia S, Shayan ZP, BastaniTehrani M, et al. Pre-hospital emergency information system in America and England: a review. Payesh 2014; 13(4): 383-91 [In Persian].
4. Talebi B, Faryabi F. Application of GIS in road accident management. Tehran: Instruction of Intercity Rescue Bases; 2014 [In Persian].

5. Zebardast E, Mohammadi A. Site selection for postearthquake relief centers using GIS and analytic hierarchy process (AHP). Honar-Ha-Ye-Ziba 2005; 21: 5-16. [In Persian].

6. Chen AY, Yu TY, Chuang WL, Lai JS, Yeh CH, $\mathrm{Ma} \mathrm{HM}$, et al. Ambulance service area considering the disturbance of disasters on transportation infrastructure. Design Construct Maintain Bridges 2014; 44: 94-101.

7. Fatih SA. A GIS based new navigation approach for reducing emergency Vehicle's response time. Selcuk Univ J Eng Sci Technol 2017; 5(1): 47-60.

8. Schmid V. Solving the dynamic ambulance relocation and dispatching problem using approximate dynamic programming. Eur J Operat Res 2012; 219(3): 611-21.

9. Ghasemi Moghar J. General results of the general population and housing census 2016. Tehran: Plan and Budget Organization of Iran; 2017. [In Persian]. 